\title{
Enhancing the contrast and visibility of daily growth increments in fish otoliths etched by proteinase $K$ buffer
}

\author{
J. C. Shiao, C. S. Tzeng*, C. L. Leu and F. C. Chen \\ Department of Life Science, National Tsing Hua University, Hsinchu, 30043 Taiwan, \\ Republic of China
}

(Received 6 August 1998, Accepted 29 September 1998)

\begin{abstract}
The otoliths of the amphidromous gobies Stiphodon elegans and Sicyopterus japonicus, a marine eel Strophidon sathete and a freshwater fish Varicorhinus barbatulus were digested by proteinase $\mathrm{K}$ buffer $(\mathrm{PKb})$, which removed the proteins and retained the major calcified structure to reveal conspicuous daily increments. Compared with etching by ethylenediaminetetraacetate (EDTA), etching with PKb revealed more visible daily increments and enhanced the contrast. Moreover, by using $\mathrm{PKb}$, both the daily increments and annuli could be observed simultaneously. The better performance of $\mathrm{PKb}$ as an etching agent can be attributed to the digesting of predominantly only the organic matrix and leaving the calcified structure almost intact. $\mathrm{PKb}$ provides another effective means to reveal otolith microstructure so as to examine and count daily growth increments.

(C) 1999 The Fisheries Society of the British Isles
\end{abstract}

Key words: otoliths; daily growth increment; proteinase K buffer.

\section{INTRODUCTION}

Counting of the daily growth increments (DGI) in otoliths is a highly effective means of determining the age of fish (Pannella, 1971, 1974; Williams \& Bedford, 1974). DGI is a bipartite structure, consisting of an incremental zone (or L zone, Kalish et al., 1995), mainly $\mathrm{CaCO}_{3}$ and a discontinuous zone (or D zone) i.e. organic matrix (Mugiya et al., 1981). The accuracy of determining ages depends on the resolution of these increments. The conventional methods generally apply diluted $\mathrm{HCl}$ or EDTA (ethylenediaminetetraacetate) to etch the sectioned otoliths for scanning electron microscopy (SEM) observation (Campana \& Neilson, 1985). $\mathrm{HCl}$ reacts with $\mathrm{CaCO}_{3}$, subsequently producing calcium chloride, water and carbon dioxide whereas EDTA chelates calcium and removes the ions from otoliths. These two chemicals are expected to dissolve only $\mathrm{CaCO}_{3}$ but in practice, prior to the highly calcified incremental zones, the discontinuous zones rich in organic matrix are first dislodged (Mugiya et al., 1981; Watabe et al., 1982). Sometimes, this method does not discriminate easily between the incremental and discontinuous zones. This is a limitation considering the fact that the increment width is extremely narrow in several fish species (Castonguay, 1986; Campana et al., 1987; Tzeng, 1990; Lecomte-Finiger, 1992; Otake et al., 1994; Cheng \& Tzeng, 1996). Hence, a new technique capable of displaying the conspicuous DGI in otoliths for age determination is a useful advance. The

\footnotetext{
*Author to whom correspondence should be addressed: Tel.: 8863 5742765; fax: 8863 5717237; email:
} lstcs@life.nthu.edu.tw 
TABLE I. The optimal times for etching $\mathrm{CaCO}_{3}$ and digesting the organic matrix in the otoliths of fish by EDTA and proteinase $\mathrm{K}$ buffer $(\mathrm{PKb})$

\begin{tabular}{|c|c|c|c|}
\hline Species & $\begin{array}{c}\text { EDTA } \\
5 \% \mathrm{pH} 7 \cdot 4\end{array}$ & $\mathrm{PKb}$ & $\begin{array}{l}\text { Sample } \\
\text { size }\end{array}$ \\
\hline $\begin{array}{l}\text { Stiphodon elegans } \\
\text { Sicyopterus japonicus } \\
\text { Strophidon sathete } \\
\text { Varicorhinus barbatulus }\end{array}$ & $\begin{array}{l}4 \min \\
4 \min \end{array}$ & $\begin{array}{l}7 \mathrm{~min} \\
35 \mathrm{~min} \\
10 \mathrm{~h} \\
50 \mathrm{~min}\end{array}$ & $\begin{array}{r}40 \\
30 \\
1 \\
1\end{array}$ \\
\hline & $\begin{array}{l}\text { Stock solution } \\
\text { concentration }\end{array}$ & Usage & $\begin{array}{c}\text { Final } \\
\text { concentration }\end{array}$ \\
\hline $\begin{array}{l}\text { Proteinase K } \\
\text { Tri-HCl pH=8.0 } \\
\text { SDS } \\
\mathrm{NaCl}\end{array}$ & $\begin{array}{r}1 \mathrm{M} \\
20 \% \\
5 \mathrm{M}\end{array}$ & $\begin{array}{c}10 \mathrm{mg} \\
0.1 \mathrm{ml} \\
0.5 \mathrm{ml} \\
0.02 \mathrm{ml}\end{array}$ & $\begin{array}{c}1 \mathrm{mg} \mathrm{ml}^{-1} \\
0 \cdot 01 \mathrm{M} \\
1 \% \\
0 \cdot 01 \mathrm{M}\end{array}$ \\
\hline
\end{tabular}

Each chemical, stock solution concentration and its volume used are listed. Total volume of $\mathrm{PKb}$ is then brought to $10 \mathrm{ml}$ using distilled water.

present study describes a novel enzymatic method to dissolve specifically the proteins, producing better-contrasted daily increments and reducing ambiguous areas.

\section{MATERIALS AND METHODS}

Proteinase K, a non-specific proteinase, is an excellent choice to degrade the proteins since the sequence and structure of the fibrous protein of the otolith remain unknown. Only the amino acid composition of the otoliths has been determined (Degens et al., 1969; Dunkelberger et al., 1980; Asano \& Mugiya, 1993). The enzyme cleaves proteins at the $\mathrm{A}-\mathrm{X}$ bond, where $\mathrm{A}$ is aliphatic, aromatic or hydrophobic amino acid and $\mathrm{X}$ is any amino acid. It can sever proteins into free amino acids when used in large quantities over long incubation periods.

The largest among the three pairs of the otoliths, the sagitta, was used in these experiments. The otoliths were first embedded in resin (L. R. white) and polished until the core was exposed on the sectioned surface. Next, the otoliths were digested with c. $0.2 \mathrm{ml}$ proteinase $\mathrm{K}$ buffer $(\mathrm{PKb})$, in $1.5-\mathrm{ml}$ Eppendorfs at $45^{\circ} \mathrm{C}$ with gentle shaking. To shorten the reaction time, sodium dodecyl sulphate (SDS) was added to the buffer. SDS can elevate the activity of proteinase K by as much as sevenfold (Hilz et al., 1975). Nevertheless, the reaction time depended on the species and the temperature. Every few minutes or hours, otoliths were extracted from the Eppendorfs to examine the etching results under the light microscope until the optimal etching conditions were reached (Table I). Other ingredients used in the $\mathrm{PKb}$ were diluted from stock solution (Table I). After the digestion by PKb, the otoliths were dried in the oven and coated with a layer of gold for SEM (Hitachi S2300) observation. Sometimes, if SDS crystallized on the surface of otoliths, $75 \%$ alcohol could dissolve the same away easily.

\section{RESULTS}

For comparison, the sagittae from the same juveniles of amphidromous gobies Stiphodon elegans (Steindachner, 1879) and Sicyopterus japonicus (Tanaka, 1909) 

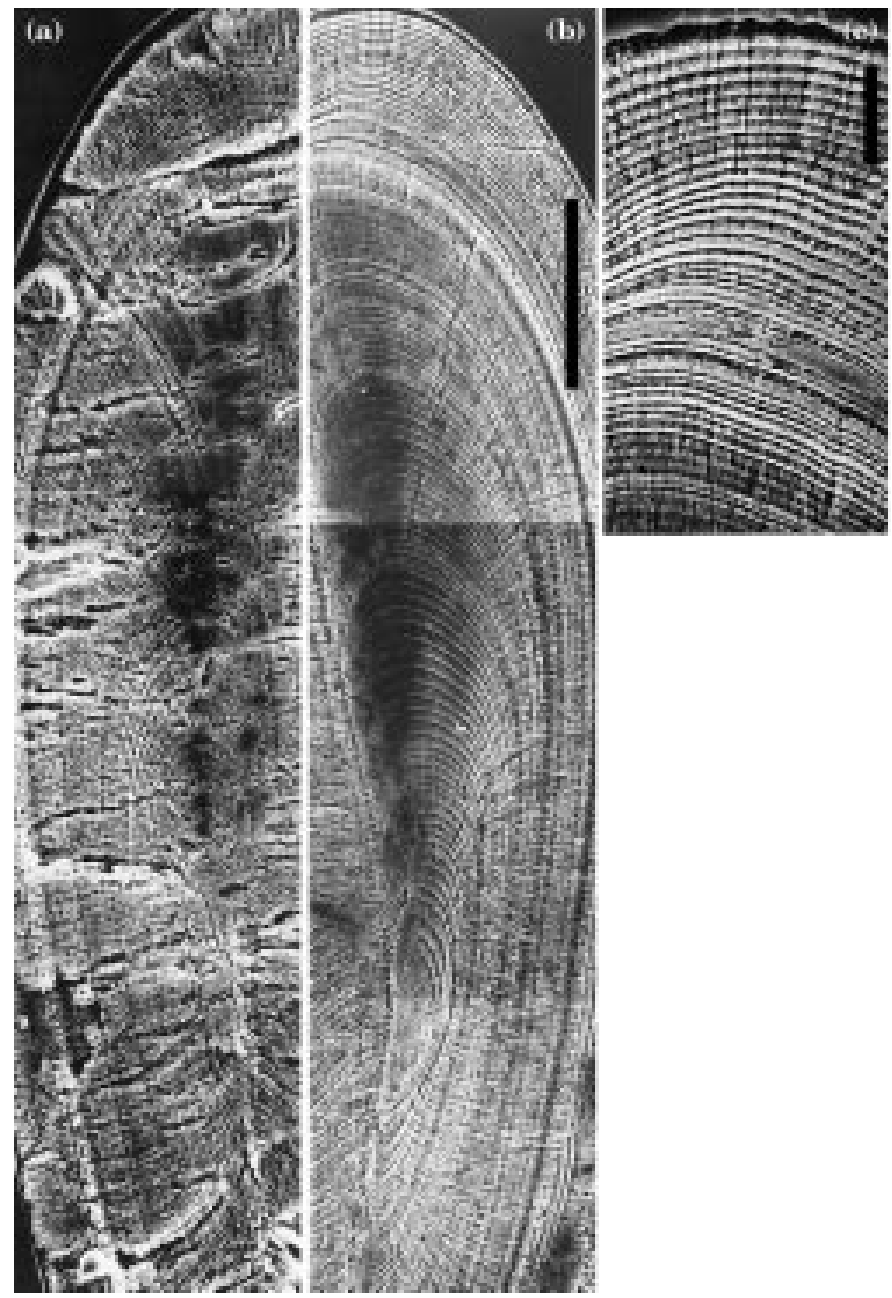

FIG. 1. Comparison of daily growth increments in the otoliths of the same individual Stiphodon elegans revealed by EDTA (a) and proteinase K buffer $(\mathrm{PKb})(\mathrm{b})$. EDTA reveals only 108 daily increments with excessively radial-direction etching. PKb digests organic matrix homogeneously and leaves 117 wider incremental zones. Partial magnification (c) provides a more detailed view of how $\mathrm{PKb}$ etches the otolith. Scale bars: (a), (b) $50 \mu \mathrm{m}$; (c) $10 \mu \mathrm{m}$.

were etched by both EDTA and PKb. It can be seen clearly that the DGI was more discernible by PKb treatment than by EDTA etching (Figs 1 and 2), which can be attributed to the fact that $\mathrm{PKb}$ created an intact and wider incremental zone than did EDTA. One hundred and seventeen DGIs in the otoliths of $S$. elegans and 212 increments of $S$. japonicus otolith treated with $\mathrm{PKb}$ could be counted without ambiguity. In contrast, the EDTA-treated otolith from the same individual of $S$. elegans revealed only 108 daily increments whereas the other otolith of the $S$. japonicus specimen revealed only a few DGIs (Figs 1 and 2). EDTA could not reveal more clear increments, despite numerous trials with different concentrations and reaction times. Other samples also revealed similar etching results from these two methods. According to these results, the ages may 


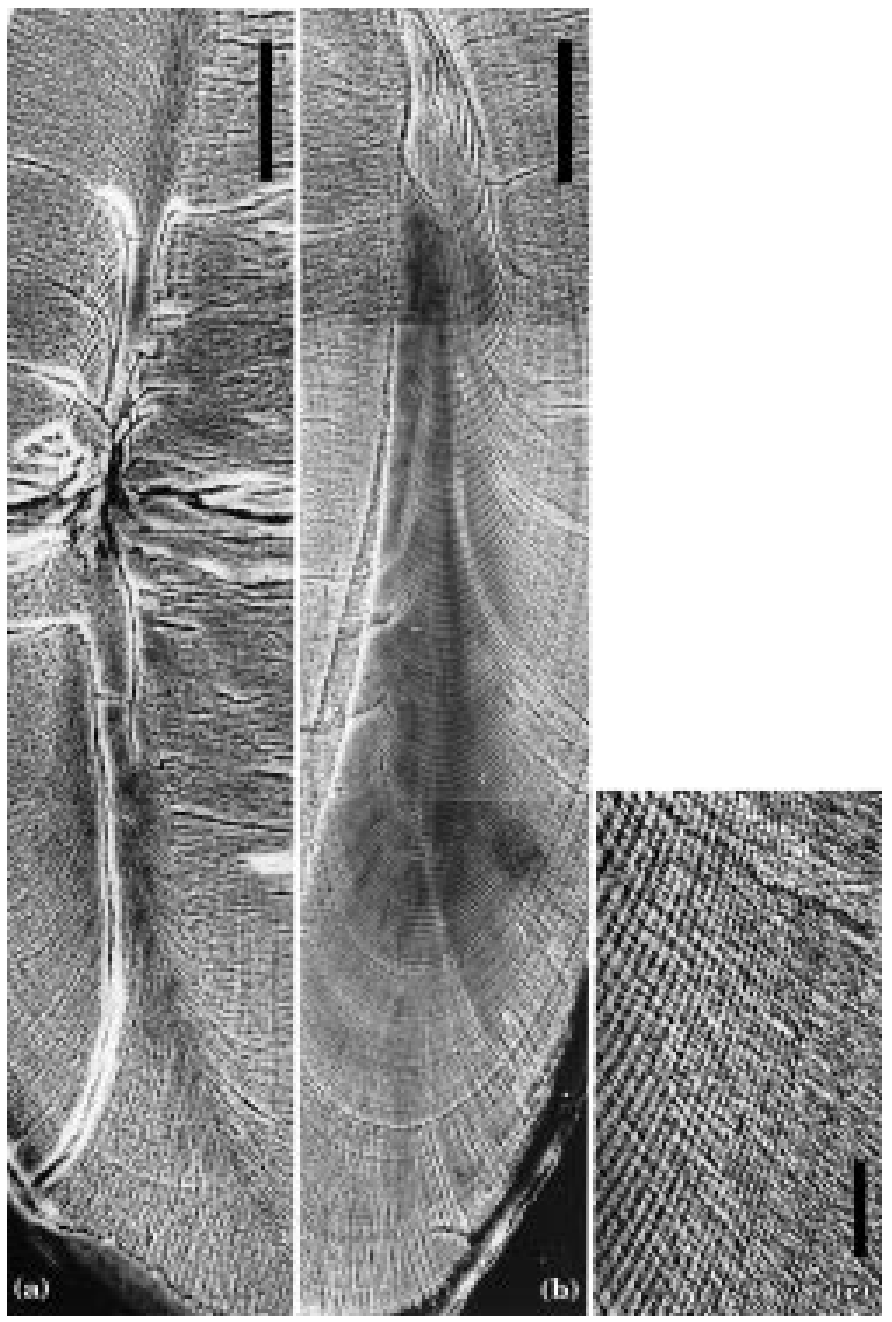

FIG. 2. EDTA cannot reveal daily growth increments in the otoliths of Sicyopterus japonicus (a). Proteinase K buffer clearly reveals 212 increments in another otolith of the same individual (b). Not exactly grinding through the longest orientation makes the otolith length in (a) shorter than in (b). Many crystals of aragonite elongated through several daily increments are observed in the magnified view (c). Scale bars: (a), (b) $50 \mu \mathrm{m}$; (c) $10 \mu \mathrm{m}$.

be underestimated using EDTA etching. Furthermore, PKb treatment is advantageous in that the microstructural pattern can be interpreted clearly. The enhanced visibility of individual increment provides practical information regarding the daily growth rate. The magnified views show that most of the organic matrix was digested away while the calcium carbonate structure was less etched after treatment with PKb [Fig. 1(c)]. Many crystals of needle-like structures, perpendicular to the daily increment, were observed [Fig. 2(c)]. These structures, extending from one daily increment to another, could make the centric increments become faint and so increase the difficulty in counting. 

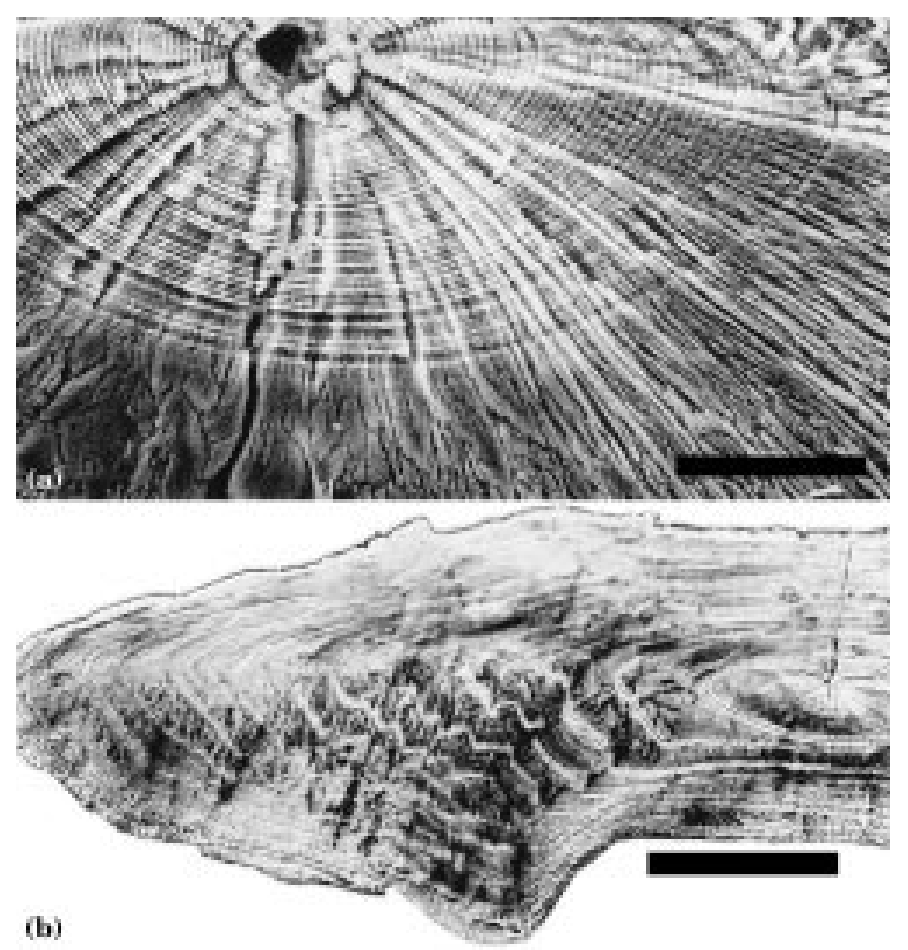

FIG. 3. Proteinase K buffer (PKb) reveals simultaneously 50 daily increments near the core (a) and 11 annuli (b) in the otolith of Strophidon sathete. The daily increments near the core appeared clearly after $1 \mathrm{~h}$ of applying PKb. Even after the digestion for $10 \mathrm{~h}$, these daily increments remain clearly discernible. Scale bars: (a) $50 \mu \mathrm{m}$, and (b) $0.5 \mathrm{~mm}$.

Next, the otoliths of a marine eel Strophidon sathete (Hamilton, 1822) total length $\left(L_{\mathrm{T}}\right) 60 \mathrm{~cm}$ and a freshwater minnow Varicorhinus barbatulus (Pellegrin, 1908) $L_{\mathrm{T}} 26 \mathrm{~cm}$ were examined to demonstrate the feasibility of PKb on adult fish. Fifty daily increments near the core and 11 annuli (11 years old) in the eel's otolith were discernible (Fig. 3). Evidently $\mathrm{PKb}$ could reveal the daily increments near the core as well as the annuli simultaneously. However, even after long-term digestion by $\mathrm{PKb}$, daily increments between annuli were not revealed. In this species, annuli replacing the daily increments, deposited in the otoliths of large fishes, appear to account reasonably for this phenomenon. An obvious drawback of this technique is the longer time required for enzyme reaction when applied to large otoliths. Revealing large otolith increments by $\mathrm{PKb}$ usually takes several hours due to the sparse deposition of their organic matrix (Degens et al., 1969). Hence, $\mathrm{PKb}$ may not be suitable to etch otoliths with highly calcified and scanty proteins.

Varicorhinus barbatulus is a slow-growth freshwater fish inhabiting extensively the mid- to upper reaches of Taiwan's streams. Water temperature plays a major role in affecting this species' distribution and $20^{\circ} \mathrm{C}$ is believed to be its maximal tolerable temperature. In the ground and polished otolith of this species, seven alternative opaque and translucent zones were observed under light microscope [Fig. 4(a)]. Similar annual increment in acanthurid fishes were verified earlier (Choat \& Axe, 1996). Translucent zones were etched into apparent annuli after 


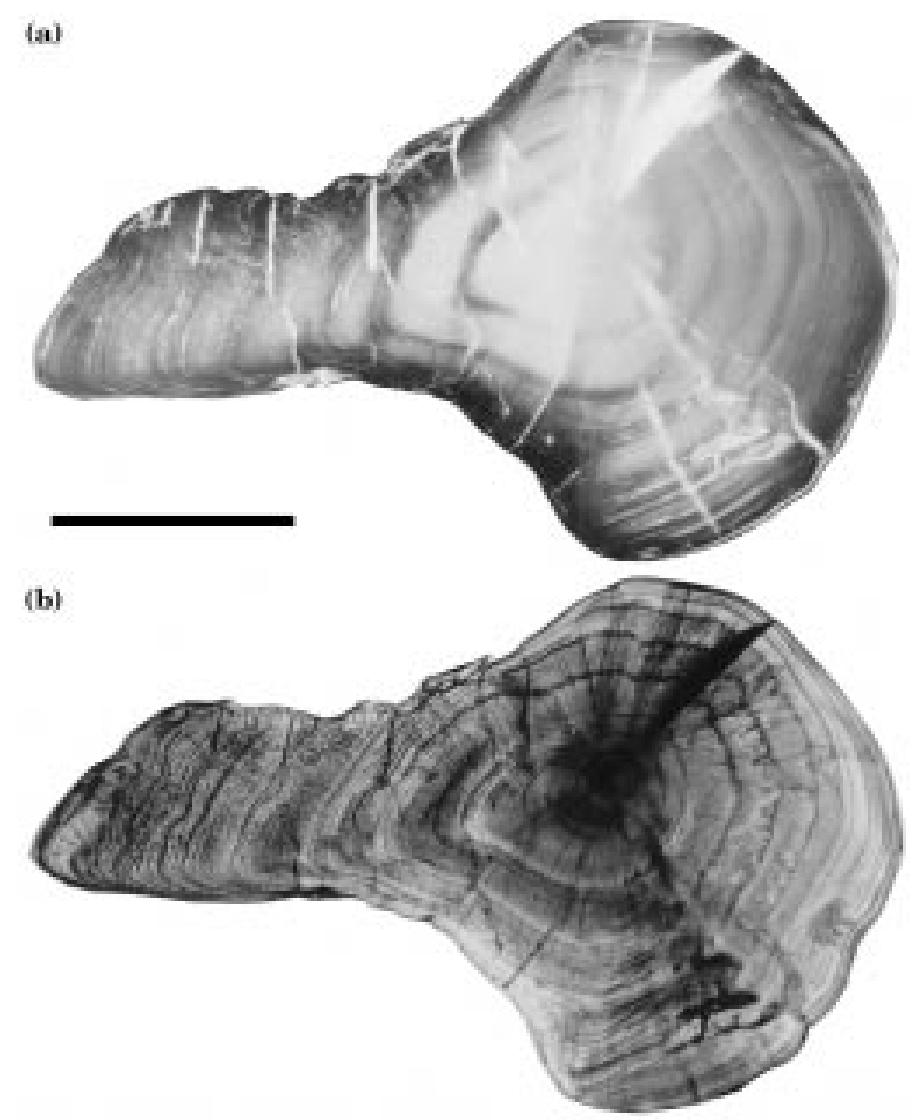

FIG. 4. (a) Seven alternate opaque and translucent zones are apparent in a Varicorhinus barbatulus otolith under light microscopy using a dark field. (b) Annuli replace the translucent zones after etching by proteinase K buffer (bright field). Scale bar: $500 \mu \mathrm{m}$.

applying $\mathrm{PKb}$ for $50 \mathrm{~min}$ [Fig. 4(b)]. The result indicated that PKb etching could aid and confirm the light microscopic observation.

\section{DISCUSSION}

The organic matrix varied from $0 \cdot 3$ to $10 \%$ in weight, depending on fish species (Degens et al., 1969). Asano \& Mugiya (1993) also reported only 2.3\% proteins by weight in tilapia (Oreochromis niloticus Linnaeus, 1758) otoliths. Therefore, proteins are only a small proportion of otoliths and are concentrated primarily in discontinuous zones. According to the understanding on incremental formation (Watabe et al., 1982), organic matrix is incorporated into the aragonite crystals, like a sandwich during the growth of incremental zones. When the crystal growth ceases, the organic matrix continues to be secreted and comes to cover the surface of the incremental zone. Thus, the discontinuous zone is formed. When treated with $\mathrm{PKb}$, therefore, the organic matrix in the discontinuous zone can be dislodged readily into a deep groove. Whereas, the organic matrix in the incremental zone, which is tightly incorporated into the aragonite crystal 
network, ought to be more difficult to digest away even though the relative organic matrix content in the incremental zone is less than that of the discontinuous zone. Nevertheless, the virtue of $\mathrm{PKb}$ is its selectivity in digesting away only the organic matrix in both discontinuous and incremental zones, leaving behind the calcium carbonate nearly intact. This should explain the increased contrast in the image we have observed. The existing wider incremental zones and narrower discontinuous zones revealed by this method make the task of counting the increments easier with less uncertainty.

On the other hand, EDTA etches organic matrix as well as calcium ions. Etching with EDTA could dissolve this bipartite structure of the otoliths simultaneously, consequently rendering a diffused image of the discontinuous and incremental zones. This makes the incremental zones revealed by EDTA generally narrower than those revealed by $\mathrm{PKb}$. Sometimes the difference in dissolving rate between the incremental and discontinuous zone is too insignificant to reveal discernible daily increments [Fig. 2(a)]. The image from the otolith of $S$. japonicus treated with EDTA, for instance, shows no clear DGIs. Certainly, EDTA has provided effective etching in dozens of fish species whereas $\mathrm{PKb}$ has been applied to only a few species. Whether $\mathrm{PKb}$ is feasible on other species remains to be tested. Digesting the susceptible proteins away using $\mathrm{PKb}$ can offer a useful alternative to display the DGI clearly in the otolith when the conventional methods are inadequate.

The authors thank W. N. Tzeng, S. E. Campana and J. D. Neilson for helpful suggestions; and P. K. Rajan for reading the manuscript. This work was supported by National Science Council (NSC86-2621-B-007-003-A07), Republic of China.

\section{References}

Asano, M. \& Mugiya, Y. (1993). Biochemical and calcium-binding properties of water-soluble proteins isolated from otoliths of the Tilapia, Oreochromis niloticus. Comparative Biochemistry and Physiology 104B, 201-201.

Campana, S. E. \& Neilson, J. D. (1985). Microstructure of fish otoliths. Canadian Journal of Fisheries and Aquatic Sciences 42, 1014-1032.

Campana, S. E., Gagne, J. A. \& Munro, J. (1987). Otolith microstructure of larval herring (Clupea harengus): Image or reality? Canadian Journal of Fisheries and Aquatic Sciences 44, 1922-1929.

Castonguay, M. (1986). Growth of American and European eel leptocephali as revealed by otolith microstructure. Canadian Journal of Zoology 65, 875-878.

Cheng, P. W. \& Tzeng, W. N. (1996). Timing of metamorphosis and estuarine arrival across the dispersal range of the Japanese eel Anguilla japonica. Marine Ecology Progress Series 131, 87-96.

Choat, J. H. \& Axe, L. M. (1996). Growth and longevity in acanthurid fishes; an analysis of otolith increments. Marine Ecology Progress Series 134, 15-26.

Degens, E. T., Deuser, W. G. \& Haedrich, R. L. (1969). Molecular structure and composition of fish otoliths. Marine Biology 2, 105-113.

Dunkelberger, D. G., Dean, J. M. \& Watabe, N. (1980). The ultrastructure of the otolithic membrane and otolith in the juvenile mummichog, Fundulus heteroclitus. Journal of Morphology 163, 367-377.

Hilz, H., Wiegers, U. \& Adamietz, P. (1975). Stimulation of proteinase K action by denaturing agents; application to the isolation of nucleic acids and the degradation of 'masked' proteins. European Journal of Biochemistry 56, 103-108. 
Kalish, J. M., Beamish, R. J., Brothers, E. B., Casselman, J. M., Francis, R. I. C. C., Mosegaard, H., Panfili, J., Prince, E. D., Thresher, R. E., Wilson, C. A. \& Wright, P. J. (1995). Glossary for otolith studies. In Recent Developments in Fish Otolith Research (Secor, D. M., Dean, J. M. \& Campana, S. E., eds), pp. 723-729. Columbia, SC: University of South Carolina Press.

Lecomte-Finiger, R. (1992). Growth history and age at recruitment of European glass eels (Anguilla anguilla) as revealed by otolith microstructure. Marine Biology 114, 205-210.

Mugiya, Y., Watabe, N., Yamada, J., Dean, J. M., Dunkelberger, D. G. \& Shimizu, M. (1981). Diurnal rhythm in otolith formation in the goldfish, Carassius auratus. Comparative Biochemistry and Physiology 68A, 659-662.

Otake, T., Ishii, T., Nakahara, M. \& Nakamura, R. (1994). Drastic changes in otolith strontium/calcium ratios in leptocephali and glass eels of Japanese eel Anguilla japonica. Marine Ecology Progress Series 112, 189-193.

Pannella, G. (1971). Fish otoliths: daily growth layers and periodical patterns. Science 173, 1124-1127.

Pannella, G. (1974). Otolith growth patterns: an aid in age determination in temperate and tropical fishes. In The Ageing of Fish (Bagenal, T. B., ed.), pp. 28-39. London: Unwin Brothers.

Tzeng, W. N. (1990). Relationship between growth rate and age at recruitment of Anguilla japonica elvers in a Taiwan estuary as inferred from otolith growth increments. Marine Biology 107, 75-81.

Watabe, N., Tanaka, K., Yamada, J. \& Dean, J. M. (1982). Scanning electron microscope observations of the organic matrix in the otolith of the teleost fish Fundulus heteroclitus and Tilapia nilotica. Journal of Experimental Marine Biology and Ecology 58, 127-134.

Williams, R. \& Bedford, B. C. (1974). The use of otoliths for age determination. In The Ageing of Fish (Bagenal, T. B., ed.), pp. 114-123. London: Unwin Brothers. 